\title{
Protective effect of Ruta Chalepensis L. extract on oxidative stress and liver-kidney function induced by polymicrobial sepsis in rats
}

Mohamed Kacem (1), Gaëlle Simon(2), Aïda Elleuch (3), Fatma Makni Ayadi(3), Tahia Boudawara (4) and Abdelfattah Elfeki (1)

(1) Laboratory of Animal Ecophysiology, Life Sciences Department, Sfax Faculty of Science, University of Sfax, BP1171, 3000 Sfax, Tunisia.

(2) Laboratory of Western Brittany of Nuclear Magnetic Resonance, University-U.E.B., France

(3) Biochemistry laboratory, CHU Habib Bourguiba, Sfax, 3029 Sfax, University of Sfax, Tunisia.

(4) Anatomopathology laboratory, CHU Habib Bourguiba, Sfax, 3029 Sfax, University of Sfax, Tunisia.

Corresponding author: Pr. Abdelfattah Elfeki and Mohamed Kacem

Tel.: +216 74268 858; fax: +216 74274437 (A. Elfeki), Tel.:+216 20849 122; fax: + 216 74274437 (M. Kacem)

E-mail address: Abdelfattah.EIFeki@fss.rnu.tn (A. Elfeki) mohamedkacem2008@yahoo.fr (M. Kacem)

\section{ABSTRACT}

Sepsis, a systemic inflammatory disease developed after an infectious insult and remains the major cause of death in intensive care units. The aim of this study was to examine the protective effect of the ethanolic extract of Ruta chalepensis L. (ERC) against oxidative stress and liver-kidney functions in cecal and ligation puncture (CLP) rats. In vitro, the results showed that ERC rich in phenolic compounds possessed important antioxidant activity. In vivo, CLP-induced oxidative stress evidenced by the increase of the TBARS and decrease in the enzymatic antioxidants (SOD, CAT, GPX) in liver and kidney. Moreover, CLP induced liver-kidney toxicities showed by an increase in the ALT, AST, PAL, LDH, BUN and creatinine in the plasma. However, the administration of ERC to CLP-rats prevents all these disorders. Positive action of ERC was confirmed by histo-pathological examination. Therefore this study suggests that ERC could be a potential therapeutic agent for sepsis treatment.

KEY-WORDS: Antioxidant; cecal ligation and puncture; oxidative stress; Ruta chalepensis L.; Sepsis.

\section{Council for Innovative Research}

Peer Review Research Publishing System

Journal: Journal of Advances in Chemistry

Vol. 10, No. 1

editorjaconline@gmail.com

www.cirjac.com/ojs 


\section{INTRODUCTION}

Sepsis presents a systemic inflammation disease specifically related to an infectious insult from agents such as bacteria, pathogenic fungi, yeasts and viruses. Sepsis, leading to multiple organ failure, including renal, liver and cardiovascular failure, disseminated intravascular coagulation (DIC) and acute respiratory distress syndrome (ARDS) remains a leading cause of mortality and morbidity in intensive care units (ICU) [1-3]. The most frequent sites of infection are the lungs, abdomen and urinary tract. Sepsis generally occurs in immunocompromised patients, the elderly, or patients undergoing procedures in which significant bacterial contamination may occur [4].

Sepsis is associated with heightened oxidative stress [5]. Indeed, various studies have shown that sepsis is associated with an increased oxygen free radicals formation including hydrogen peroxide $\left(\mathrm{H}_{2} \mathrm{O}_{2}\right)$, superoxide anions $\left(\mathrm{O}^{*}\right)$ and hydroxyl radicals $\cdot \mathrm{OH}$ and a decreased antioxidant potential such as superoxide dismutase (SOD), catalase (CAT) and glutathione (GSH) [6]. Thus, the homeostatic balance normally present in cells between radical formation and protection by antioxidant defenses system is disturbed and subsequently leads to oxidative stress [7]. The generation of oxygen free radicals might be enhanced, leading to membrane damage, LPO, mitochondrial damage and initiation or aggravation of diverse pathological states [8- 9]. The pro-inflammatory properties of ROS include endothelial damage, chemotactic factors formation, neutrophils recruitment, lipid peroxidation, DNA damage, tumor necrosis factor-alpha (TNF- $\alpha)$ and interleukin-1-beta (IL-1 $\beta$ ) release and peroxynitrite formation [1].

Ruta chalepensis L. (R. chalepensis L.), commonly known as Fijel, belongs to the family of Rutaceae. It is a native herb of the Mediterranean region [10] but it is also cultivated in many parts of the world in temperate and tropical countries [11]. Researcher has shown that this plant has biological activities such as antifungal, antioxidant, phytotoxic, abortive, depressant, antidotal, ant-inflammatory and a depressant effect on the central nervous system [10, 11-19]. R. chalepensis L. known as a medicinal plant since ancient times is currently used in many countries (Saudi Arabia, India, china and Africa) for the treatment of various disorders [15]. Ruta species has characterized the presence of more than 120 compounds of different classes of natural products. Indeed, the leaves and young stems contain alkaloids, phenols, amino acids, furocoumarins, saponins, coumarins, tannins, volatile oil, glycosides, sterols and triterpenes [20- 21].

This study aimed to investigate the in vitro protective effects of $R$. chalepensis $L$. extract by evaluating the free radicals scavenging capacity using the DPPH, ABTS and TAC. In vivo, the present paper was carried out to examine the protective effects of $R$. chalepensis $L$. aerial parts extract on the liver and kidney damage assessed by lipid peroxidation, antioxidant enzymes capacities and cell damage biomarkers form rat during sepsis induced by cecal and ligation puncture (CLP) model.

\section{MATERIALS AND METHODS}

\subsection{Chemicals}

2,2-Diphenyl-1-picrylhydrazyl (DPPH), ascorbic acid, gallic acid, Butylated hydroxytoluene (BHT), thiobarbituric acid (TBA), glutathione (GSH), bovine serum albumin (BSA), 2,2'-azino-bis(3-ethylbenzothiazoline-6-sulphonic acid) (ABTS), potassium persulfate and Trolox, were purchased from Sigma, France. Trichloroacetic acid (TCA), hydrogen peroxide $\left(\mathrm{H}_{2} \mathrm{O}_{2}\right)$, 5,5'-Dithio-bis (2-nitrobenzoic acid) (DTNB) Folin-Ciocalteu reagent, sodium carbonate $\left(\mathrm{Na}_{2} \mathrm{CO}_{3}\right)$, and other solvents were of analytical grade and were freshly prepared in distilled water.

\subsection{Plant materials}

Fresh plant material (stem and leaves) was collected in March 2011 in Chebba region (Mahdia, Tunisia, latitude $35.23^{\circ}$ and longitude $11.11^{\circ}$ ). The plant was identified and authenticated by a botanist (Pr. Mohamed Chaieb, Department of Botany, Faculty of Sciences, University of Sfax, Tunisia), according to the Flora of Tunisia [22-23]. The vouchers specimen was deposited at the herbarium of the department of botany in the cited institute.

\subsection{Preparation of extract}

The collected plant material was dried in shade at $25^{\circ} \mathrm{C}$ for two weeks, grinded with a blender for 15 min. The powder was soaked in ethanol with shaking for 3 days and extracted three times at room temperature $\left(22^{\circ} \mathrm{C}\right)$. The extract was then filtered and the solvents evaporated using a freeze drier and stored at $4^{\circ} \mathrm{C}$ in the dark until a further analysis. This was used as ethanol extract of Ruta chalepensis L. (ERC).

\subsection{Phytochemical screening}

The preliminary phytochemical screening was performed according to the Harborne [24, 25] methods. Ethanol extract of Ruta chalepensis L. (ERC) was subjected to chemical tests for the presence of sterols, triterpenoids, carotenoids, tropolons, quinons, flavonoids and alkaloids.

\subsection{Determination of total phenolic content (TPC)}

Total phenolic content (TPC) was measured by the modified Folin-Ciocalteu procedure [26]. Briefly, $50 \mu \mathrm{l}$ of sample $(1 \mathrm{mg} / \mathrm{ml})$ was mixed with $250 \mu \mathrm{l}$ of Folin-Ciocalteu reagent. After $3 \mathrm{~min}, 50 \mu \mathrm{l}$ of sodium carbonate $\left(\mathrm{Na}_{2} \mathrm{CO}_{3}\right)(20 \%$, w/v) was added to the mixture and the final volume was adjusted to $5 \mathrm{ml}$ with distilled water. After incubation for 30 min at room temperature, the absorbance was read at $727 \mathrm{~nm}$ using a spectrophotometer. Gallic acid was used as a standard for the calibration curve. The phenolic content was expressed as mg gallic acid equivalents (GAEs)/gram of dry extract using the linear equation based on the calibration curve. 


\subsection{Total antioxidant capacities (TAC)}

The total antioxidant capacities (TAC) of $R$. chalepensis L. ethanol extract (ERC) were evaluated by the phosphomolybdenum method of Prieto et al. [27]. This assay is based on the reduction of Mo (VI) to Mo (V) by the sample and the subsequent formation of a green phosphate/Mo (V) complex at acidic $\mathrm{pH}$. An aliquot of $0.1 \mathrm{ml}$ of methanolic sample solution $(1 \mathrm{mg} / \mathrm{ml})$ was mixed with $1 \mathrm{ml}$ of the reagent solution $(0.6 \mathrm{M}$ sulfuric acid, $28 \mathrm{mM}$ sodium phosphate and 4 $\mathrm{mM}$ ammoniummolybdate). The tubes were capped and incubated in a boiling water bath at $95^{\circ} \mathrm{C}$ for $90 \mathrm{~min}$. After incubation, the samples had cooled to room temperature and the absorbance of the test sample was measured at $695 \mathrm{~nm}$ against a blank. The blank contained $1 \mathrm{ml}$ of reagent solution and the appropriate volume of the same solvent used for the sample and it were incubated under same conditions as the rest of the samples. Ascorbic acid was used as a standard for the calibration curve. The TAC of the sample was expressed as milligrams of ascorbic acid equivalents (AAEs)/gram of dry extract.

\subsection{Scavenging activity of $A B T S$ radical cation}

The trolox equivalent antioxidant capacity (TEAC) assay, which measures the reduction of the radical cation of 2,2'-azinobis(3-ethylbenzothiazoline-6-sulphonic acid) (ABTS) by antioxidants was performed as previously described [28]. Briefly, ABTS was dissolved in water to a $7 \mathrm{mM}$ concentration and the ABTS radical cation (ABTS ${ }^{+}$) was produced by adding potassium persulfate to a final concentration of $2.45 \mathrm{mM}$. The completion of radical generation was obtained in the dark at room temperature for $12-16 \mathrm{~h}$ before use. For the study, the ABTS ${ }^{+}$solution was diluted with ethanol to adjust its absorbance at $734 \mathrm{~nm}$ to $0.70 \pm 0.02$. For the photometric assay $1 \mathrm{~mL}$ of the $\mathrm{ABTS}^{+}$solution and $100 \mu \mathrm{l}$ of antioxidant solution were mixed for $45 \mathrm{~s}$. After $5 \mathrm{~min}$, measurement was performed at $734 \mathrm{~nm}$, using methanol as the blank. A calibration curve was prepared with different concentrations of Trolox $(0-20 \mu \mathrm{M})$. Results were expressed as millimolar concentration of Trolox per gram of dry extract

\subsection{DPPH free radical-scavenging capacity}

Antioxidant scavenging activity was studied using 2,2-Diphenyl-1-picrylhydrazyl free radical (DPPH), according to the method of Kirby and Schmidt [29], with some modifications. Briefly, $1 \mathrm{ml}$ of a $4 \%(\mathrm{w} / \mathrm{v})$ solution of DPPH radical in methanol was mixed with $1 \mathrm{ml}$ of sample solution in methanol (different concentrations). The mixture was shaken and incubated for $20 \mathrm{~min}$ in the dark at room temperature. Scavenging capacity was read spectrophotometrically by monitoring the decrease of the absorbance at $517 \mathrm{~nm}$. Lower absorbance of the reaction mixture indicates a higher free radicalscavenging activity.

The free radical scavenging activity of each solution was then calculated as percent inhibition according to the following equation:

Scavenging activity (\%) $=\left(A_{\text {blank }}-A_{\text {sample }} / A_{\text {blank }}\right) \times 100$

Where $A_{\text {blank }}$ is the absorbance of the DPPH solution in the absence of sample, and $A_{\text {sample }}$ is the absorbance of the sample. Extract concentration providing $50 \%$ inhibition $\left(\mathrm{IC}_{50}\right)$ of $\mathrm{DPPH}$ was calculated from the graph of percentage inhibition against extract concentration. Ascorbic acid was used as reference compounds.

\subsection{Animals and treatments}

Adult male Wistar rats (weighing approximately 160-240 g) used for the experiment were supplied by the Central Pharmacy of Tunisia (SIPHAT, Tunisia). All animals were kept in cages and maintained in a controlled environment (temperature, $22 \pm 3^{\circ} \mathrm{C}$; minimum relative humidity, 40\%) in an animal hose with a $12 \mathrm{~h}$ light/dark cycle. The rats were fed with a commercial balanced diet (SICO, Sfax, Tunisia) and drinking water was offered ad libitum. All the experimental procedures were carried out in accordance with international guidelines for care and use of laboratory animals [30]

\subsection{Sepsis induction-cecal ligation and perforation surgery}

Polymicrobial sepsis was achieved using the cecal ligature and puncture (CLP) model in groups of rats according to the method described by Wichterman et al. [31].The surgical procedure was carried out under anesthesia by i.p. injection of chloral hydrate. Briefly, after shaving and cleaning the ventral abdominal wall with alcohol, a midline incision $(2-3 \mathrm{~cm})$ was made and the cecum was carefully exposed to avoid damage to the blood vessels. After the placement of a partially occlusive ligature around the right colon junction, ten punctures were performed in the cecum with a 20-gauge sterile needle, allowing the passage of some fecal material in the abdominal cavity. The cecum was then gently squeezed to extrude a small amount of feces from the perforation site, returned to the peritoneal cavity and the abdomen was closed in two layers. Sham rats were operated on in the same manner except that cecum ligation and puncture were not performed. After surgery, normal saline $(3 \mathrm{ml} / 100 \mathrm{~g} \mathrm{b.w})$ was given subcutaneously to all rats to prevent dehydration. All rats were kept separately in their metabolic cages with free access to food and water.

The septic condition was characterized by muscular wasting at the hind limb level, hair erection, hyper-excitability, restlessness in locomotion, sub-conjunctival hemorrhage and increased spleen weight. In the sham-operated rats, the cecum was exposed, manipulated and returned to the peritoneal cavity without being punctured.

\subsection{Experimental design}

The ethanol extract of $R$. chalepensis $\mathrm{L}$. was dissolved in saline solution ( $\mathrm{NaCl} 0.9 \%)$. The suspensions were freshly prepared each time and injected intraperitonially (i.p.) into the rats with a volume of $1 \mathrm{ml} / 100 \mathrm{~g}$ body weight (BW). Control animals received the same volume of vehicle (saline solution only). 
After 4 weeks of acclimatization, the rats were allocated randomly to four experimental groups of ten animals each with free access to food and water.

-Group I: served as the vehicle-treated sham (control group) in which a sham operation but no CLP was performed. These animals received the solution saline $(\mathrm{NaCl} 0.9 \%)$ daily by intraperitoneally injection for $48 \mathrm{~h}$.

-Group II: served as the Ruta-treated sham (ERC group) in which a sham operation but no CLP was performed. These animals received the ethanol extract $R$. chalepensis L. (20 mg kg ${ }^{-1}$ BW) daily by intraperitoneally injection for $48 \mathrm{~h}$.

-Group III: served as the vehicle-treated CLP (CLP group). These animals underwent laparotomy followed by CLP as described above and received the solution saline $(\mathrm{NaCl} 0.9 \%)$ daily by intraperitoneally injection for $48 \mathrm{~h}$.

-Group IV: served as the Ruta-treated CLP (CLP+ERC group). These animals underwent laparotomy followed by CLP as described above and received the ethanol extract $R$. chalepensis $\mathrm{L}$. (20 mg kg ${ }^{-1} \mathrm{BW}$ ) daily by intraperitoneally injection for $48 \mathrm{~h}$.

At the end of experiments, the rats were weighed and rapidly sacrificed by cervical decapitation in order to minimize the handling stress, and the arterio-venous blood samples were collected in heparin-containing tubes from all the experimental groups. Plasma was immediately separated by centrifugation of the blood at $3000 \mathrm{rpm}$ for $15 \mathrm{~min}$ at $4^{\circ} \mathrm{C}$, divided into aliquots and stored at $-20^{\circ} \mathrm{C}$ until used for biochemical assays.

The thiobarbituric acid-reactive substances (TBARs) and the antioxidant enzyme activities (superoxide dismutase (SOD), catalase (CAT) and glutathione peroxidase (GPX)) were determined in liver and kidney extracts.

\subsection{Preparation of cytosolic extract}

In brief, about $1 \mathrm{~g}$ of rat organs liver or kidney was cut into small pieces and homogenized in $2 \mathrm{ml}$ of ice-cold Tris Buffered Saline (TBS, $\mathrm{pH} 7.4)$, centrifuged at $9000 \times \mathrm{g}\left(4^{\circ} \mathrm{C}, 20 \mathrm{~min}\right)$. Supernatants were collected and stored at $-80^{\circ} \mathrm{C}$ until use.

\subsection{Biochemical assays}

\section{Estimation of protein level}

Total protein content was determined by the method of Lowry et al. [32] using the Folin reagent and bovine serum albumin (BSA) as standard at $490 \mathrm{~nm}$.

\section{TBARS measurements}

The lipid peroxidation level in tissues was estimated by measuring thiobarbituric acid-reactive substances (TBARs) and expressed in terms of malondialdehyde (MDA) content using the method of Yagi [33]. $125 \mu$ l of supernatants were mixed with $50 \mu \mathrm{l}$ of TBS, pH 7.4 and $125 \mu$ of $20 \%$ trichloroacetic acid (TCA) containing $1 \%$ butylated hydroxytoluene (BHT) in order to discard proteins. After centrifugation $\left(1000 \times \mathrm{g}, 4^{\circ} \mathrm{C}, 10 \mathrm{~min}\right), 200 \mu \mathrm{l}$ of the new supernatants were mixed with $40 \mu \mathrm{l}$ of $\mathrm{HCl}(0.6 \mathrm{M})$ and $160 \mu \mathrm{l}$ of $120 \mathrm{mM}$ thiobarbituric acid (TBA) dissolved in $26 \mathrm{mM}$ trishydroxymethyl aminomethane (Tris). The mixture was heated at $80^{\circ} \mathrm{C}$ for $10 \mathrm{~min}$, and after cooling, the absorbance was read at $530 \mathrm{~nm}$ against a reference blank. TBARs level was calculated by using an extinction coefficient of $1.56 \times 10^{5} \mathrm{M}^{-1} \mathrm{~cm}^{-1}$.

\section{Measurement of catalase (CAT) activity}

The catalase (CAT) activity was estimated according to Aebi [34]. The used reaction mixture contained $780 \mu l$ of phosphate buffer $(0.1 \mathrm{mM}, \mathrm{pH} 7.4), 200 \mu \mathrm{l}$ of $50 \mathrm{mM} \mathrm{H}_{2} \mathrm{O}_{2}$ and $20 \mu \mathrm{l}$ of tissue homogenate. The reaction started by adding $\mathrm{H}_{2} \mathrm{O}_{2}$ and its decomposition was observed by following the decrease in absorbance at $240 \mathrm{~nm}$ for $1 \mathrm{~min}$. One unit of CAT activity is defined as the amount of enzymes required to decompose $1 \mu \mathrm{mol}$ of hydrogen peroxide in $1 \mathrm{~min}$. The enzyme activity was expressed in international units (I.U.), i.e., in $\mu$ mole of $\mathrm{H}_{2} \mathrm{O}_{2}$ consumed $/ \mathrm{min} / \mathrm{mg}$ protein, at $25^{\circ} \mathrm{C}$.

\section{Estimation of superoxide dismutase (SOD) activity}

The superoxide dismutase (SOD) activity was estimated by measuring its ability to inhibit the photo reduction of nitroblue terazolium (NBT) according to the method of Asada et al. [35]. One unit of SOD activity is defined as the amount of enzyme required to inhibit the photo reduction of NBT by $50 \%$. The activity was expressed as units $/ \mathrm{mg} \mathrm{protein,} \mathrm{at} 25^{\circ} \mathrm{C}$.

\section{Measurement of glutathione peroxidase (GPx) activity}

The glutathione peroxidase (GPX) activities were determined in the cytosolic fractions according to the method of Paglia and Valentine [36]. Tissue homogenate was mixed with $400 \mu \mathrm{l}$ of $0.1 \mathrm{mM}$ glutathione (GSH) and $200 \mu \mathrm{l}$ of $67 \mathrm{mM}$ of $\mathrm{KNaHPO}_{4}(\mathrm{pH}=7.8)$. After $5 \mathrm{~min}$ of pre-incubation at $25^{\circ} \mathrm{C}, 200 \mu \mathrm{l}$ of $1.3 \mathrm{M}$ of $\mathrm{H}_{2} \mathrm{O}_{2}$ were added. After 10 min, the mixture was treated with $1 \mathrm{ml}$ of $1 \%$ TCA and centrifuged at $3000 \times \mathrm{g}$ and $4^{\circ} \mathrm{C}$ during $10 \mathrm{~min}$. Supernatants were homogenized with $0.32 \mathrm{M}$ of $\mathrm{Na}_{2} \mathrm{HPO}_{4}$ and $1 \mathrm{mM}$ of 5,5'-Dithio-bis (2-nitrobenzoic acid) (DTNB). The enzyme activity was spectrophotometrically measured at $412 \mathrm{~nm}$ and expressed as $\mu$ moles of $\mathrm{GSH}$ reduced $/ \mathrm{min} / \mathrm{mg}$ protein.

\section{Estimation of biochemical parameters in liver and kidney}

The biochemical parameters such as lactate dehydrogenase (LDH), phosphatase alkaline (PAL), aspartate aminotransferase (AST), alanine aminotransferase (ALT), blood urea nitrogen (BUN) and creatinine were analyzed in the plasma using commercial kits according to the manufacturer's directions. 


\subsection{Histopathological studies}

Forty-eight hours after CLP, tissue samples of liver and kidney were removed for histological analysis. Each sample was fixed by immersion in a Bouin solution for 24. The sample was then embedded into paraffin, sliced into 3- $\mu \mathrm{m}$ sections, and stained with hematoxylin-eosin. The slides were examined classically with a photonic microscope to determine histopathological lesions.

\subsection{Statistical analysis}

Data are reported as mean \pm standard error to the mean (SEM) for at least 6 determination throughout the study. The statistical analyses were calculated using a one-way analysis of variance (ANOVA), followed by Student's t-test and the significance was accepted at $\mathrm{p}<0.05$

\section{RESULTS}

\subsection{Phytochemical characterization}

Results of the preliminary phytochemical screening performed according to the Harborne method are illustrated in Table 1. In fact, the chemical tests performed for, sterols, triterpenoids, carotenoids, tropolons and quinons were negative. However, the chemical tests performed for flavonoids and alkaloids were positive in ERC extract. The quantification of total phenolics of ERC extract was performed using the Folin Ciocalteu reagent. Analysis showed that ERC contains $178 \pm 0.02 \mathrm{mg}$ gallic acid equivalents (GAEs)/g of dry extract (Table 2).

Table 1. Chemical groups present in R. chalepensis L. ethanol extract (ERC).

\begin{tabular}{|c|c|c|c|c|c|c|}
\hline Extract & T1 & T2 & T3 & T4 & T5 & T6 \\
\hline ERC & - & - & - & - & + & + \\
\hline
\end{tabular}

T1: test of sterols and/or triterpenoids; T2: test of carotenoids and/or triterpenoids; T3: tropolons test; T4: quinons test; T5: flavonoids test; T6: alkaloids test; -: no reaction; +: positive reaction

\subsection{Total antioxidant capacities (TAC)}

The total antioxidant capacity (TAC) of $R$. chalepensis L. ethanol extract (ERC) was measured spectrophotometrically through phosphomolybdenum method, which is based on the reduction of $\mathrm{Mo}(\mathrm{VI})$ to $\mathrm{Mo}(\mathrm{V})$ by the antioxidant compound and the subsequent formation of a green phosphate/Mo (V) complex at acidic $\mathrm{pH}$ with a maximal absorption at $695 \mathrm{~nm}$ [27]. Analysis showed that TAC of ERC extract was of the order $123.85 \pm 6.48 \mathrm{mg}$ ascorbic acid equivalents (AAEs)/g of dry extract (Table2).

\subsection{Scavenging activity of $A B T S$ radical cation}

ABTS by reacting with potassium persulfate, produces $A B T S$ radical cation $\left(\mathrm{ABTS}^{+}\right)$, a blue green chromogen with maximum absorption at $734 \mathrm{~nm}$. The extent of decolorization is significant indicator of antioxidant activity of the sample. Indeed, the reaction of antioxidants on ABTS radical cation is due to its hydrogen donating availability which is visually observed by transformation of color radical cation $\left(\mathrm{ABTS}^{+}\right)$into colorless $\mathrm{ABTS}$. Analysis showed that ERC extract. presents a capacity ABTS radical scavenging of the order of $0.095 \pm 0.001 \mathrm{mmol} / \mathrm{g}$ of dry extract (Table 2).

Table 2. Total phenol content (TPC), total antioxidant capacity (TAC) and scavenging activity of ABTS radical cation of $\boldsymbol{R}$. chalepensis L. ethanol extract (ERC).

\begin{tabular}{|c|c|c|c|}
\hline \multirow{2}{*}{ Extract } & $\begin{array}{c}\text { TPC } \\
\text { (mg of GAEs/g of dry extract) }^{\text {a }}\end{array}$ & $\begin{array}{c}\text { TEAC } \\
\text { (mmoles/g of dry extract) }^{\text {a }}\end{array}$ & $\begin{array}{c}\text { TAC } \\
\text { (AAEs/g of dry extract) }^{\text {a }}\end{array}$ \\
\hline ERC & $178 \pm 0.02$ & $0.095 \pm 0.001$ & $123.85 \pm 6.48$ \\
\hline
\end{tabular}

${ }^{a}$ Values expressed are means \pm SD of three parallel measurements

\subsection{DPPH radical scavenging activity}

DPPH is a stable free radical that shows maximum absorbance at $517 \mathrm{~nm}$. When DPPH radicals encounter a protondonating substrate, such as an antioxidant, the radicals are scavenged and the absorbance is reduced [37]. The decrease in absorbance is taken as a measure of radical scavenging activity. This is a widely used method to investigate the scavenging activity of some natural compounds. 
As can be seen in Fig. 1, the scavenging activity of ERC extract is concentration-dependent. The IC50 value of ERC is $0.14 \mathrm{mg} / \mathrm{ml}$, whereas the IC50 of ascorbic acid is $40 \mu \mathrm{g} / \mathrm{ml}$.

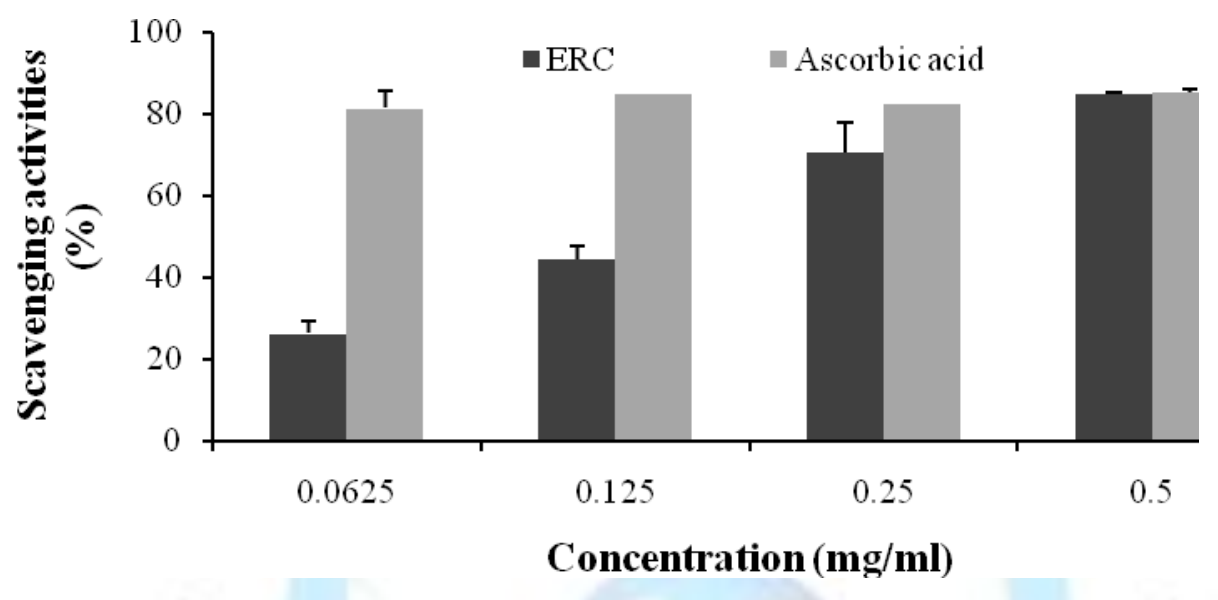

Fig 1: free radical-scavenging capacities of ERC and ascorbic acid as positive control measured by DPPH assay. Values expressed are means \pm SEM of three parallel measurements.

\subsection{Biochemical parameters in liver and kidney}

LDH, AST, ALT and PAL activities increased significantly by $38.1 \%, 21.3 \%, 17.9 \%$ and $80 \%$, respectively, in the CLP group compared with the control group. These hepatic enzymes are known to be released in blood in the event of cellular destruction [38] and increased activities indicate some degree of cytolysis. Treatment with ERC extract markedly attenuated the increases and ameliorated all indices related to liver dysfunction by $24.6 \%, 15.3 \%, 9.8 \%$ and $32.6 \%$, respectively at $48 \mathrm{~h}$ after CLP (Fig. 2).
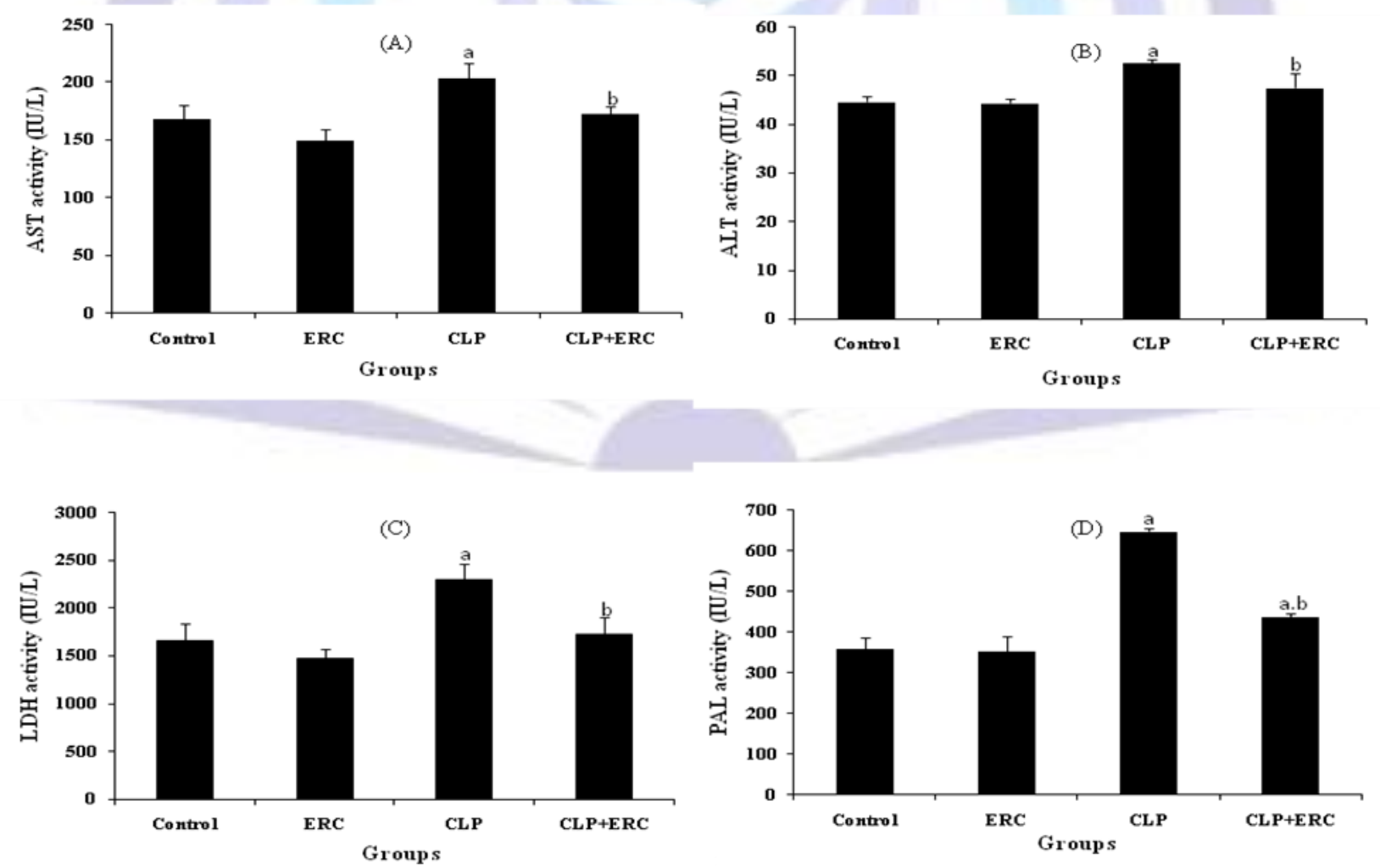

Fig 2: Effect of CLP and R. chalepensis L. ethanol extract (ERC) treatment on the AST (A), ALT (B), LDH (C), and PAL (D) activities. Values are mean \pm SEM; $n=6$ AST, ALT, LDH and PAL-IU/I

${ }^{a}$ As compared to control group: $p<0.05 .{ }^{b}$ As compared to CLP group: $p<0.05$ 
Blood urea nitrogen (BUN) and Creatinine were measured as an index of renal failure. Significantly higher plasma creatinine and BUN were observed in the CLP group as compared to normal. This increase was about of $15.4 \%$ and $30.6 \%$, respectively. After treatment with ERC extract, we noticed that these biochemical parameters levels significantly decreased at $48 \mathrm{~h}$ after CLP (by 10, 4\% and 16.2\% respectively) (Fig. 3).
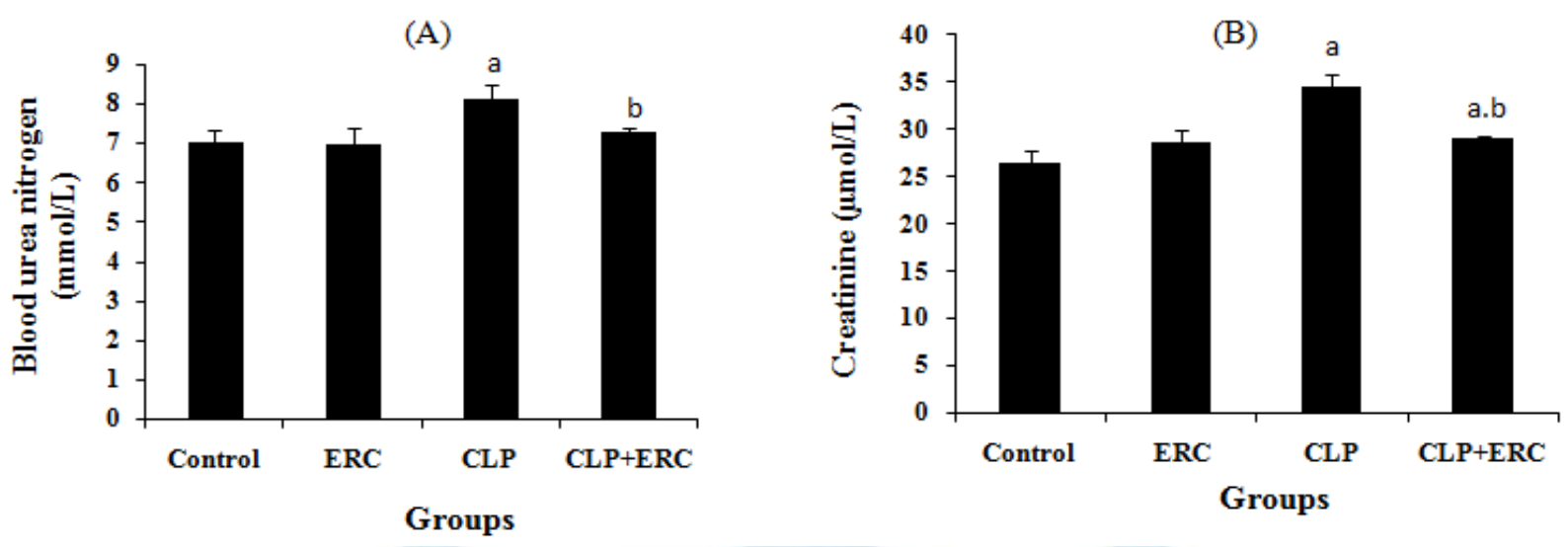

Fig 3: Effect of CLP and R. chalepensis L. ethanol extract (ERC) treatment on blood urea nitrogen (BUN) (A) and creatinine (B) levels. Values are mean $\pm S E M ; n=6$. BUN-mmol/l and creatinine- $\mu \mathrm{mol} / \mathrm{l}$

${ }^{a}$ As compared to control group: $p<0.05$. ${ }^{b}$ As compared to CLP group: $p<0.05$

\subsection{Hepatic and renal lipid peroxidation}

Lipid peroxidation levels in the liver and kidney of rats subjected to the different treatments were measured according to Yagi method [33]. MDA levels, an end-product of lipid peroxidation, in both liver and kidney samples were significantly higher by $85.7 \%$ and $39.3 \%$ respectively in the CLP group compared to the control group (sham group). This increase indicates lipid peroxidation at the cytoplasmic membrane. Treatment with ERC extract decreased significantly MDA levels in both tissues at $48 \mathrm{~h}$ after CLP by $29.4 \%$ and $15.4 \%$, respectively (Fig. 4 ).
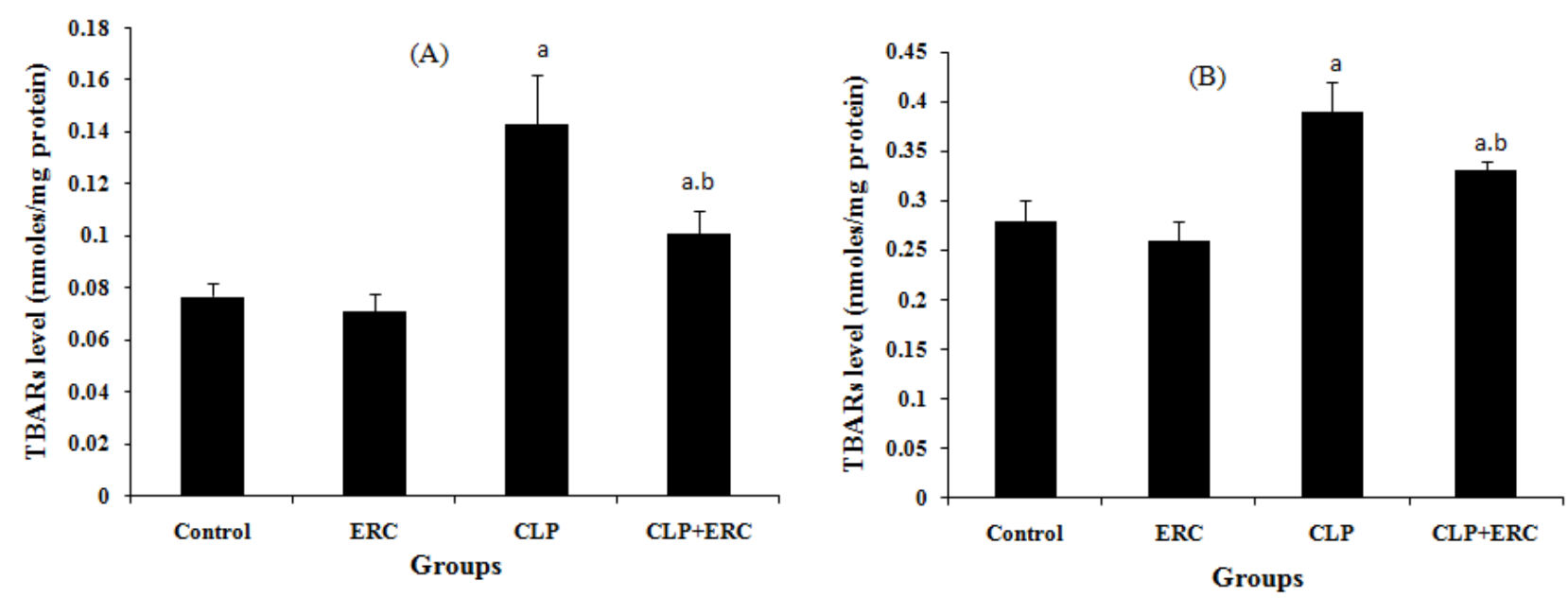

Fig 4: Lipid peroxidation levels (TBARs) in liver (A) and kidney (B) of control, CLP, ERC and treated septic rats. Values are mean $\pm S E M ; n=6$. TBARs rate-nmoles TBARs $/ \mathrm{mg}$ protein.

${ }^{a}$ As compared to control group: $p<0.05$. ${ }^{b}$ As compared to CLP group: $p<0.05$

\subsection{Hepatic and renal antioxidant enzyme activities}

Activities of some major enzymes involved in the defense against oxidative stress, SOD, CAT and GPX, were measured in control, septic and treated rats using the methods of Asada et al. [35], Aebi [34] and Paglia and Valentine [36], respectively. As shown in Fig. 5 and 6, the liver and kidney activities of theses antioxidant enzymes decreased in CLP group compared to control rats. Indeed, the reduction in the activities of antioxidant enzymes SOD, Cat, and GPX were 
about $43.2 \%, 52 \%$ and $53.3 \%$ respectively for the liver and $43.2 \%, 58.4 \%$ and $45 \%$ respectively for the kidney. A protective effect was observed when treating septic rats by ERC extract during $48 \mathrm{~h}$. Actually, the antioxidant enzymes activities SOD, Cat and GPX were higher by $26 \%, 29.7 \%$ and $71.4 \%$ respectively in liver and $37.5 \%, 103 \%$ and $54.5 \%$ respectively in kidney compared to the CLP group.
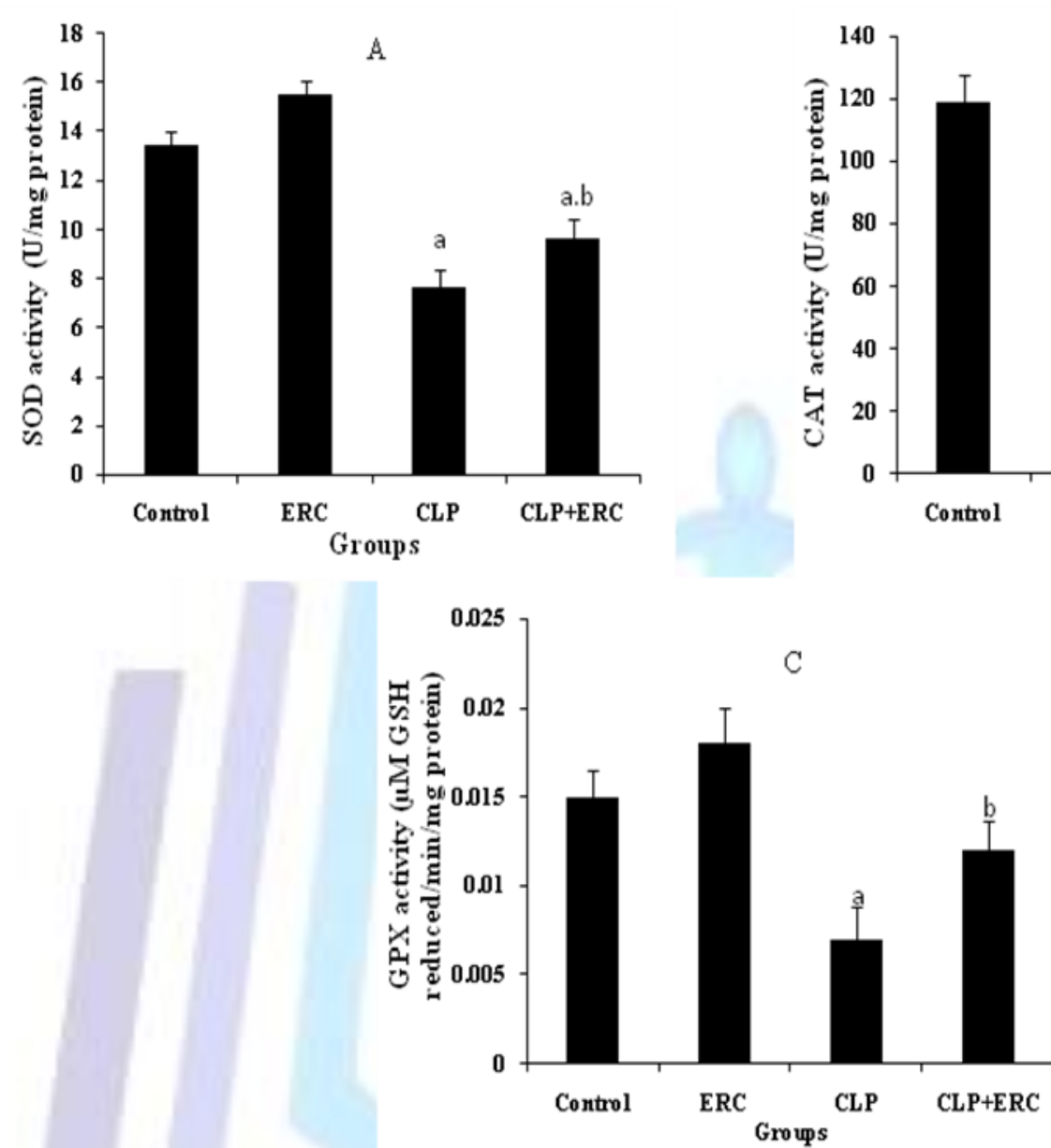

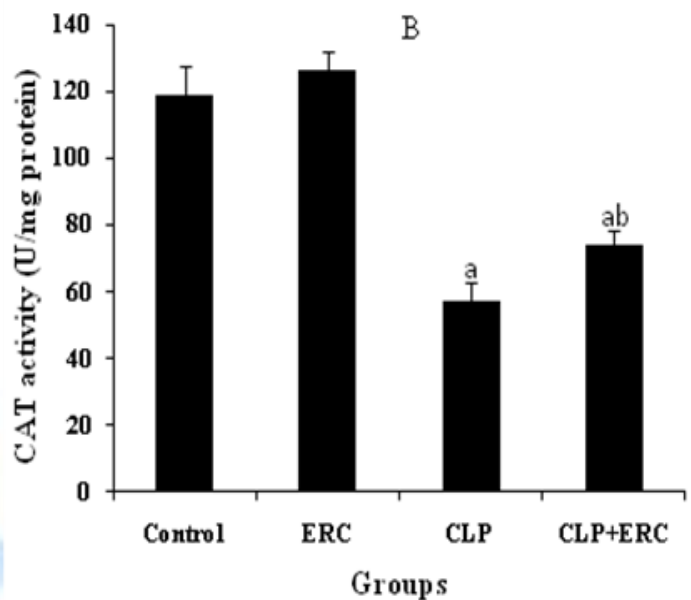

Groups

Fig 5: Activities of superoxide-dismutase (SOD) (A), Catalase (CAT) (B) and glutathione peroxidase (GPx) (C) in liver of control, ERC, CLP and treated septic rats. Values are mean $\pm S E M ; n=6$. SOD activity units $/ \mathrm{mg}$ protein. Catalase activity- $\mu$ moles $\mathrm{H}_{2} \mathrm{O}_{2}$ consumed $/ \mathrm{min} / \mathrm{mg}$ protein. GPX activity- $\mu$ moles of $\mathrm{GSH}$ reduced $/ \mathrm{min} / \mathrm{mg} \mathrm{protein}$.

${ }^{a}$ As compared to control group: $p<0.05$. ${ }^{b}$ As compared to CLP group: $p<0.05$ 

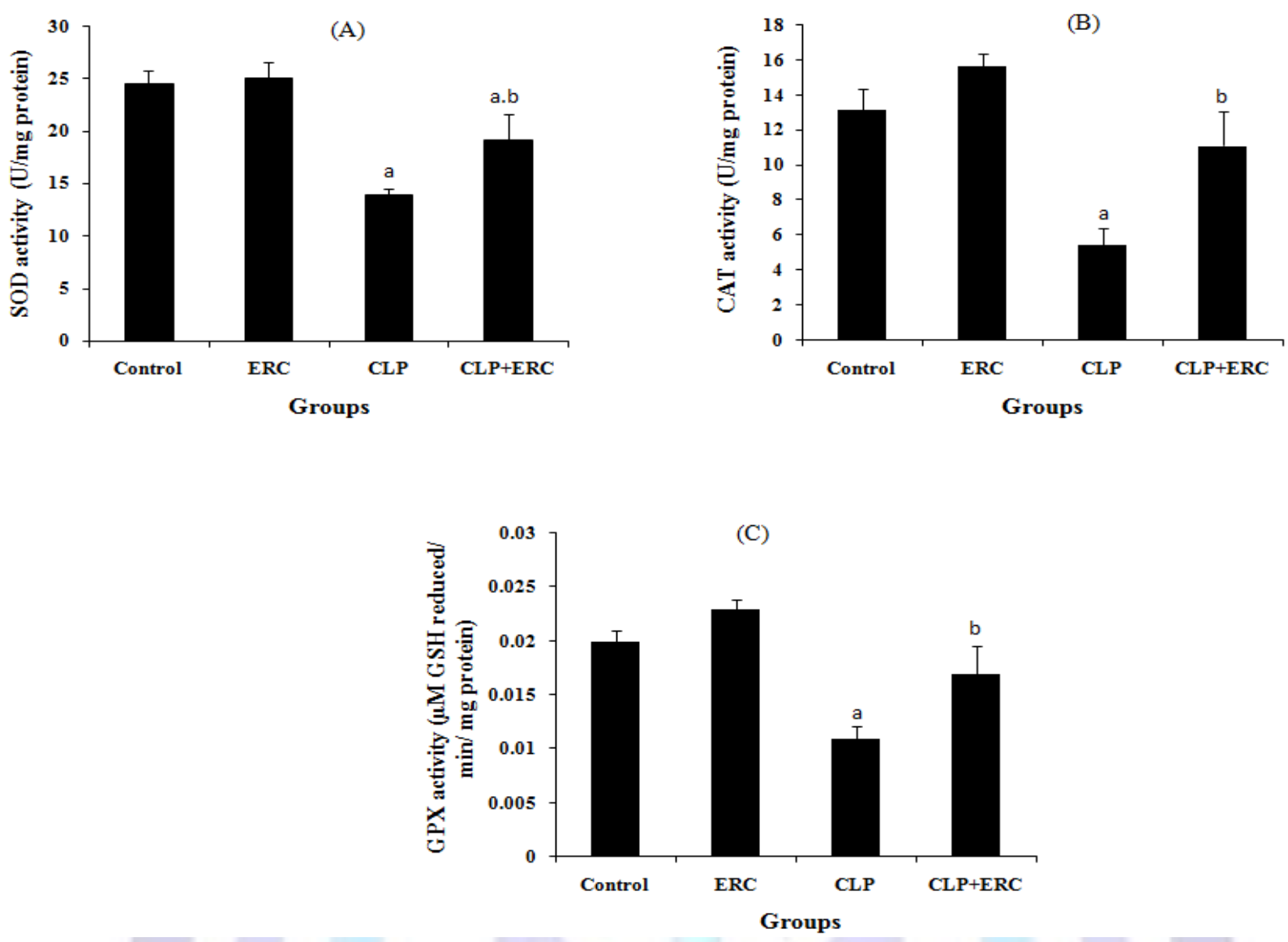

Fig 6: Activities of superoxide-dismutase (SOD) (A), Catalase (CAT) (B) and glutathione peroxidase (GPx) (C) in Kidney of control, ERC, CLP and treated septic rats. Values are mean \pm SEM; $n=6$. SOD activity units $/ \mathrm{mg}$ protein. Catalase activity- $\mu$ moles $\mathrm{H}_{2} \mathrm{O}_{2}$ consumed $/ \mathrm{min} / \mathrm{mg}$ protein. GPX activity- $\mu$ moles of $\mathrm{GSH}$ reduced $/ \mathrm{min} / \mathrm{mg} \mathrm{protein}$.

\section{${ }^{a}$ As compared to control group: $p<0.05$. ${ }^{b}$ As compared to CLP group: $p<0.05$}

\subsection{Histopathological findings}

The histological features reveal normal cell structure in the liver of control animals. However, the liver of CLP-rats marked histopathological changes such as inflammatory cell infiltration, necrosis and fatty cyst apparition in tissue sections. An ameliorative effect was obtained in CLP rats by treatment with ERC extract. The histological pattern was almost normal in rats treated with ethanol extract of Ruta chalepensis L. (ERC) alone (Fig.7). 

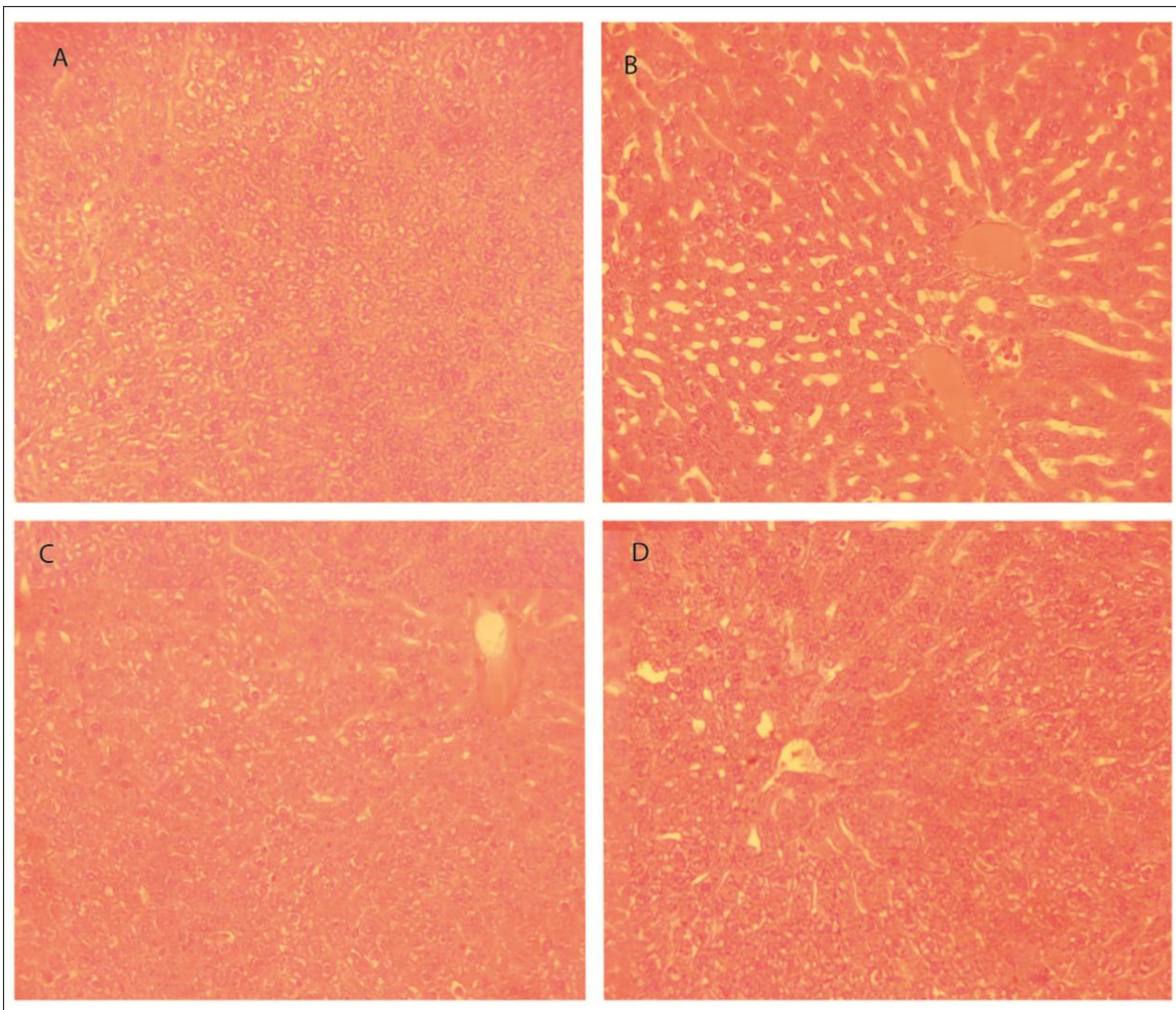

Fig 7: (A) hepatic tissue of control rat showing normal appearance; (B) hepatic tissue of septic rats showed inflammatory cell infiltration, necrosis and fatty cyst apparition; (C) hepatic tissue of sham-rats treated with ERC extract, showing normal appearance; (D) liver of septic rats treated with ERC extract showing the amelioration of histopathological changes observed in CLP group. Original magnification $100 \mathrm{X}$

The section of the Kidney from a control rat showed a normal architecture. However, the kidney of CLP-rats exhibited an increase in bowman space and glomerular atrophy, whereas, examination of the kidney of septic rats treated with ERC extract revealed potential protective action evidence by the amelioration of histopathological changes observed in kidney of CLP group (Fig. 8). 

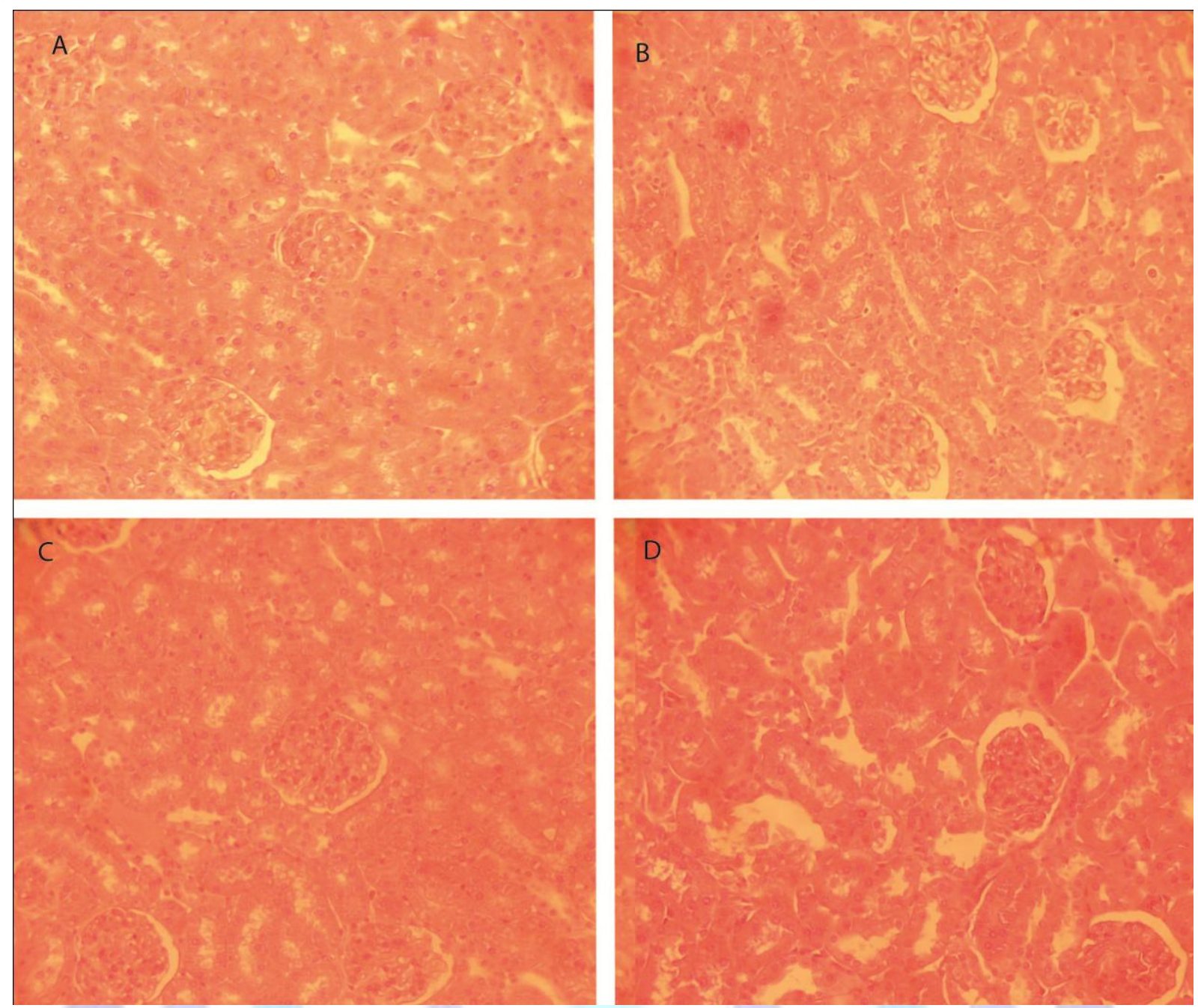

Fig 8: (A) renal tissue of control rat showing normal appearance; (B) In septic kidney-rats an increase in bowman space and glomerular atrophy $(C)$ renal tissue of sham-rats treated with ERC extract, showing normal appearance; (D) septic kidney-rats treated with ERC extract; showing the amelioration of histopathological changes observed in CLP group. Original magnification $100 \mathrm{X}$

\section{DISCUSSION}

In the present study, sepsis model was induced by cecal ligation and puncture (CLP), which mimics the clinical situation of bowel perforation and bacterial infection in humans [39]. Several experimental studies have shown that CLP causes the inoculation of colonic content into the peritoneal cavity and results in episodic bacteremia and systemic changes such as hyperpyrexia, leukocytosis and tachycardia. These also reflect the progress of clinical human sepsis that occurs as a consequence of the invasion of the body by gram-negative or gram-positive bacteria, fungi and probably by viruses and parasites. Sepsis leads to immune cell activation with the release of reactive oxygen species (ROS). These inflammatory mediators are important for killing pathogens, but if the response is over-stimulated, then it may cause systemic infection in distal organs and can lead to death. There is a considerable body of evidence for redox imbalance and oxidative stress in sepsis [40-42]. Oxidative stress mediated by oxygen-derived free radicals which include hydrogen peroxide and hydroxyl radicals is an important cause of cell membrane damage. Several studies have identified the sources of free radicals in sepsis. Some of them are the NADPH oxidase system [43-44], xanthine oxireductase [45]. Reactive oxygen species are highly reactive and react with biological macromolecules, producing lipid peroxides, inactivating proteins, and mutating DNA. Lipid peroxidation, mediated by free oxygen radicals, is believed to be an important cause of destruction and damage to cell membranes, since the polyunsaturated fatty acids of the cellular membranes are degraded by this process with a consequent disruption of membrane integrity. Lipid peroxidation can cause changes in membrane fluidity and permeability and, thus, increase the rate of protein degradation, which will eventually lead to cell lysis [46]. A report has found a strong link between the reduction of oxidative stress, antioxidant drugs, and survival improvement in the CLP model of sepsis [47], supporting the hypothesis that oxidative damage may probably be one of several important factors that lead to cell damage, organ dysfunction and death.

In the present study, we observed that the induction of sepsis after CLP surgery resulted in significant oxidative damage in liver and kidney tissues, as evidenced by an increased lipid peroxidation with a concomitant decrease in SOD, Cat and GPX activities. The imbalance between antioxidant/oxidant brought about by sepsis induced by cecal and ligation 
puncture (CLP) was also observed by several authors. Thus [48] showed that the MDA levels in the liver, kidney, heart, lung, diaphragm and brain were significantly higher in the CLP group than in the control. Similarly, it was demonstrated that macrophage oxidative stress and mitochondrial superoxide production increased after CLP [49]. The malondialdehyde (MDA) level, a major product of lipid peroxidation, was shown to be an effective marker in oxidative stress in sepsis [42] The same applies to other researchers who showed that lipid products levels increased from 40 to $80 \%$ above basal values as a result of oxidative stress [50-51]. Increased concentrations of lipid peroxidation products are found in sepsis induced by cecal ligation and perforation in rats and humans [52-53]. An excessive level of lipid peroxidation, (as a marker of oxidative damage) expressed by thiobarbituric acid reactive substances (TBARs) accumulation, is known to be a critically important phenomenon resulting from oxidative stress [54].

Antioxidants can control sepsis-induced ROS either by directly scavenging free radicals or by enhancing the endogenous antioxidant defense system. Indeed, the main enzymes involved in protection against damage caused by oxidative stress in chronic sepsis are CAT, SOD and GSH. These antioxidant enzymes are considered to be a primary defense that prevents biological macromolecules from oxidative damage and restricts the cytotoxic effects of toxic free radicals. SOD is an enzyme that catalyses the dismutation of superoxide anion $\left(\mathrm{O}_{2}{ }^{-*}\right)$ to $\mathrm{O}_{2}$ hydrogen peroxide $\left(\mathrm{H}_{2} \mathrm{O}_{2}\right)$ [55]. The latter molecule is the substrate of CAT and GPX. When a cell has increased levels of SOD without a proportional increase in CAT or GPX, a large amount of $\mathrm{H}_{2} \mathrm{O}_{2}$ could react with metal ions, via the Fenton chemistry, and generate hydroxyl radical $(\cdot \mathrm{OH})$, which is the most harmful radical [56]. Catalase and glutathione peroxidase, selenium-containing enzymes which require the presence of reduced GSH for its action, both catalyze the conversion of $\mathrm{H}_{2} \mathrm{O}_{2}$ to $\mathrm{H}_{2} \mathrm{O}$. Thus, the decrease of superoxide dismutase enzyme SOD in CLP group could be due to a feedback inhibition or oxidative inactivation of enzyme protein due to ROS generation excess [57]. The inhibition of the catalase activity of CLP group is suggestive of enhanced synthesis of superoxide anion $\left(\mathrm{O}_{2}{ }^{-}\right)$that is a powerful inhibitor of catalase [58]. The free radicals attack hepatic and renal cells, leading to hepatic and renal toxicity and dysfunction that are supported by the increase in LDH, AST, ALT and PAL activities and blood urea nitrogen and creatinine levels [59- 61]. There is increasing evidence that oxidative stress plays an important role in the development of sepsis-induced multiorgan failure [62]. Organ failure often begins with respiratory failure, followed by intestinal, hepatic, renal, hematologic, and cardiac failure; the exact order may vary because of preexisting disease or the precipitation insult [63]. Indeed, previous study, carried by Yun et al. [61] showed that induction of sepsis after CLP surgery causes marked histo-pathological changes in heart, kidney, liver, and lung samples such as congestion, inflammatory cell infiltration, necrosis, and degeneration compared to sham operation.

Defense against sepsis-induced oxidative stress consists of antioxidants synthesized in the tissues and exogenous antioxidants. The present paper reveals that oxidative damage induced by sepsis was partially abolished by $R$. chalepensis $\mathrm{L}$. ethanol extract. The protective effect of $R$. chalepensis $\mathrm{L}$. is connected with its components that possess scavenging free radical properties. In order to evaluate the total antioxidant activity of natural compounds present in $R$. chalepensis L., three methods were used in the present study that is DPPH free radical scavenging capacity, total antioxidant capacities (TAC) and scavenging activity of ABTS radical cation. These findings suggest that flavonoids from $R$. chalepensis L. are responsible for the antioxidant effect. Independent studies have confirmed the presence of antioxidant phenolic compounds in the aerial part of Ruta gravoelens L. related plant [64]. Other studies supported by Khlifi et al. [65] have showed that $R$. chalepensis L. extracts possess antioxidant activities, which supports their ethnopharmacological use. Flavonoids widely distributed in plants have the ability to inhibit oxidative damage. Indeed, these flavonoids have the potential to function as in vitro antioxidants by scavenging superoxide anion [66], singlet oxygen [67] lipid peroxy-radicals [68-69], and/or stabilizing free radicals involved in oxidative processes through hydrogenation or complexing with oxidizing species [70]. Flavonoids existing in $R$. chalepensis $L$., in addition to their free radical scavenging properties also enhance the expression of intracellular endogenous antioxidants such as superoxide dismutase (SOD), catalase, and GPX by maintaining their activities higher compared to the CLP group. Histopathological changes were ameliorated by $R$. chalepensis $\mathrm{L}$. treatment. These morphological improvements with $R$. chalepensis $\mathrm{L}$. treatment were also confirmed by assessing biochemical parameters. In an in vivo model, Ruta gravoelens L., a related plant has been found to reduce oxidative stress by decreasing TBARS level and increasing antioxidant enzymes activities such as SOD, catalase and GPX in liver and heart in hypercholesteromic rats [56]. Similarly, Ashour et al. [71] showed that treatment with the ethanolic extract of $R$. chalepensis $\mathrm{L}$. could reduce oxidative stress as well as inflammation in hypercholesteromic rats. In in vitro experiments, Ruta gravoelens L. extract was found to scavenge hydroxyl radical and inhibit lipid peroxidation [72]. According to the available literature [73], $R$. chalepensis L. plant contains approximately $2-5 \%$ of rutin. Recently, several studies have reported that rutin decreases nitric oxide and reduces inducible nitric oxide synthase (iNOS) protein in BALB/c mice pretreated with lipopolysaccharide (LPS) [74]. The same applies to other studies carried out by lauk et al. [15] that showed that $R$. chalepensis L. extract inhibited LPS-induced nitric oxide production in BALB/C mice.

\section{CONCLUSION}

It can be concluded that Ruta chalepensis L. ethanol extract has a powerful antioxidant activity, sufficient to prevent oxidative stress induced by sepsis produced by the technique of cecal ligature and puncture (CLP) model. Indeed, this extract inhibits lipid peroxidation and induces antioxidant enzymes activities such as SOD, CAT and GPX, consequently attenuating liver and kidney dysfunction. Thus, we propose that $R$. chalepensis $L$. is a potential therapeutic medication for the care of clinical septic patients.

\section{DECLARATION OF INTEREST}

The authors declare no conflict of interest. 


\section{ACKNOWLEDGEMENTS}

This work was supported by the Tunisian Ministry of Higher Education and Scientific Research. We are grateful to Mr. Hafedh BJAOUI, an English teacher at the Sfax Faculty of Sciences, for having proofread this paper.

\section{ABBREVIATIONS}

AAEs, ascorbic acid equivalents; ALT, alanine aminotransferase; ARDS, Acute respiratory distress syndrome; AST, aspartate aminotransferase; BHT, butylated hydroxytoluene; BSA, bovine serum albumin; BUN, blood urea nitrogen; CAT, Catalase; CLP, cecal ligation and puncture; DIC, disseminated intravascular coagulation; DPPH, 2,2-Diphenyl-1picrylhydrazyl; DTNB, 5, 5'-Dithio-bis (2-nitrobenzoic acid); GAEs, gallic acid equivalents; GPX, glutathione peroxidase; GSH, glutathione; ICU, Intensive care units; IL-1 $\beta$, interleukin-1-beta; iNOS, inducible nitric oxide synthase; LDH, lactate dehydrogenase; MDA, malondialdehyde; NBT, nitroblue terazolium; PAL, phosphatase alkaline; ROS, reactive oxygen species; SIRS, systemic inflammatory response syndrome; SOD, superoxide dismutase; TAC, total antioxidant capacity; TBARS, Thiobarbituric acid-reactive substances; TBS, Tris Buffered Saline; TCA, trichloroacetic acid; TEAC, trolox equivalent antioxidant capacity; TNF- $\alpha$, tumor necrosis factor-alpha; TPC, total phenolic content.

\section{REFERENCES}

[1] Cassol-jr, O.J., Comim, C.M., Silva, B.R., Hermani, F.V., Constantino, L.S., Felisberto, F., Petronilho, F., Hallak, J.E., De Martinis, B.S., Zuardi, A.W., Crippa, J.A., Quevedo, J., Dal-Pizzol, F. 2010. Treatment with cannabidiol reverses oxidative stress parameters, cognitive impairment and mortality in rats submitted to sepsis by cecal ligation and puncture. Brain. Res. 1348, 128-38.

[2] Scott, M.J., Godshall, C.J., Cheadle, W.G. 2002. Jaks, STATs, Cytokines, and Sepsis. Clin. Diagn. Lab. Immunol. 9 , 1153-1159.

[3] Hotchkiss, R.S., Karl, I.E. 2003. The pathophysiology and treatment of sepsis. N. Engl. J. Med. 348, 138-150.

[4] Aytekin, F.O., Teke, Z., Aydin, C., Kabay, B., Yenisey, C., Sacar, S., Demir, E.M., Tekin, K.2007. Effects of a membrane-permeable radical scavenger, Tempol, on healing of colonic anastomoses in the cecal ligation and puncture model of polymicrobial sepsis in rats. Am. J. Surg. 193, 723-729.

[5] Tsai, K., Hsu, T., Kong, C., Lin, K., Lu, F. 2000. Is the endogenous peroxyl-radical scavenging capacity of plasma protective in systemic inflammatory disorders in humans? Free Radic. Biol. Med. 28, 926-933.

[6] Koksal, G.M., Sayilgan, C., Aydin, S., Oz, H. and Uzun, H. 2004. Correlation of plasma and tissue oxidative stresses in intra-abdominal sepsis. J. Surg. Res. 122, 180-183.

[7] Peralta, J.G., Llesuy, S., Evelson, P., Carreras, M.C., Flecha, B.G., Poderoso, J.J. 1993. Oxidative stress in skeletal muscle during sepsis in rats. Circ. Shock. 39, 153-9.

[8] Silbergeld, E.K., Waalkes, M., Rice, J.M. 2000. Lead as a carcinogen: experimental evidence and mechanisms of action. Am. J. Ind. Med. 38, 316-323.

[9] Patrick, L. 2006. Lead toxicity part II: the role of free radical damage and the use of antioxidants in the pathology and treatment of lead toxicity. Altern. Med. Rev. 11, 114-127.

[10] Gonzalez-Trujano, M.E., Carrera, D., Ventura-Martinez, R., Cedillo-Portugal, E., Navarrete, A. 2006. Neuropharmacological profile of an ethanol extract of Ruta chalepensis L. in mice. J. Ethnopharmacol. 106, $129-135$.

[11] Zeichen de Sa, R., Rey, A., Arganaraz, E., Bindstein, E. 2000. Perinatal toxicology of Ruta chalepensis (Rutaceae) in mice. J. Ethnopharmacol. 69, 93-98.

[12] Milesi, S., Massot, B., Gontier, E., Bourgaud, F., Guckert, A. 2001. Ruta graveolens L.: a promising species for the production of furanocoumarins. Plant Science. 161: 189-199.

[13] De Feo, V., De Simone, F., Senatore, F. 2002. Potential allelochemicals from the essential oil of Ruta graveolens. Phytochemistry. 61, 573-578.

[14] Kabouche, Z., Benkiki, N., Seguin, E., Bruneau, C. 2003. A new dicoumarinyl ether and two rare furocoumarins from Ruta montana. Fitoterapia. 74, 194-196.

[15] lauk, L., Mangano, K., Rapisarda, A., Ragusa, S., Maiolino, L., Musumeci, R., Costanzo, R., Serra, A., Speciale, A. 2004. Protection against murine endotoxemia by treatment with Ruta chalepensis L., a plant with anti-inflammatory properties. J. Ethnopharmacol. 90, 267-272.

[16] De Freitas, T.G., Augusto, P.M., Montanari, T. 2005. Effect of Ruta graveolens L. on pregnant mice. Contraception. 71, 74-7.

[17] Meepagala, K.M., Schrader, K.K., Wedge, D.E., Duke, S.O. 2005. Algicidal and antifungal compounds from the roots of Ruta graveolens and synthesis of their analogs. Phytochemistry. 66, 2689-2695. 
[18] Raghav, S.K., Gupta, B., Agrawal, C., Goswami, K., Das, H.R. 2006. Anti-inflammatory effect of Ruta graveolens L. in murine macrophage cells. J. Ethnopharmacol. 104, 234-239.

[19] Mejri, J., Abderrabba, M., Mejri, M. 2010. Chemical composition of the essential oil of Ruta chalepensis L: Influence of drying, hydro-distillation duration and plant parts. Ind. Crop. Prod. 32, 671-673.

[20] Chen, J., Raj, N., Kim, P., Andrejko, K.M., Deutschman, C.S. 2001. Intrahepatic nuclear factor-kappa B activity and alpha 1 -acid glycoprotein transcription do not predict outcome after cecal ligation and puncture in the rat. Crit. Care. Med. 29, 589-96.

[21] Pathak, S., Multani, A.S., Banerji, P., Banerji, P. 2003. Ruta 6 selectively induces cell death in brain cancer cells but proliferation in normal peripheral blood lymphocytes: A novel treatment for human brain cancer. Int. J. Oncol. 23, 975982.

[22] Pottier-Alaptite, G. 1979. Flore de la Tunisie: Angiospermes-dicotylédones Apétales- Dialypétales. Imprimerie officielle de la République Tunisienne. 291: 293.

[23] Chaieb, M., Boukhris, M. 1998. Flore succinct et Illustré des zones arides et sahariennes de Tunisie. 49: pp. 43-44.

[24] Harborne, J.B. 1964. Biochemistry of phenolic compounds. London: Academic Press 93-111

[25] Harborne, J.B. 1973. Phytochemical methods: a guide to modern techniques of plant analysis. London: chapman and Hall Ltd, 49-188

[26] Singleton, V.L., Rossi, J.A. 1965. Colorimetry of total phenolics with phosphomolybdic- phosphotungstic acid reagents. Am. J. Enol. Vitric. 16, 144-158.

[27] Prieto, P., Pineda, M., Aguilar, M. 1999. Spectrophotometric quantitation of antioxidant capacity through the formation of a phosphomolybdenum complex: specific application to the determination of vitamin E. Anal. Biochem. 269, 337341.

[28] Laporta, O., Pérez-Fons, L., Mallavia, R., Caturla, N., Micol, V. 2007. Isolation, characterization and antioxidant capacity assessment of the bioactive compounds derived from Hypoxis rooperi corm extract (African potato). Food chem. 101, 1425-1437.

[29] Kirby, A.J., Schmidt, R.J. 1997. The antioxidant activity of Chinese herbs for eczema and of placebo herbs. J. Ethnopharmacol. 56, 103-108.

[30] Council of European Communities 1986. Council instructions about the protection of living animals used in scientific investigations. Off.J.Eur.Commun (JO 86/609/CEE) L358, 1-28.

[31] Wichterman, K.A., Baue, A.E., Chaudry, I.H. 1980. Sepsis and septic shock: a review of laboratory models and a proposal. J. Surg. Res. 29, 189-201.

[32] Lowry, O.H., Rosebrough, N.J., Farr, A.L., Randall, R.J. 1951. Protein measurement with the folin phenol reagent. J. Biol. Chem. 193, 265-275.

[33] Yagi, K. 1976. A simple Fluorometric assay for lipoperoxide in blood plasma. Biochem. Med. 15, 212-216.

[34] Aebi, H. 1984. Catalase in vitro. Methods. Enzymol. 105, 121-126.

[35] Asada, K., Takahashi, M., Nagate, M. 1974. Assay and inhibitors of spinach superoxide dismutase. Agric. Biol. Chem. $38,471-473$.

[36] Paglia, D.E., Valentine, W.N. 1967. Studies on the quantitative and qualitative characterization of erythrocyte glutathione peroxidase. J. Lab. Clin. Med. 70, 158-169.

[37] Shimada, K., Fujikawa, K., Yahara, K., Nakamura, T. 1992. Antioxidative properties of xanthum on the autoxidation of soybean oil in cyclodextrin emulsion. J. Agric. Food Chem. 40, 945-948.

[38] Vinogradova, L.F., Mirzoian, Z.H.A., Kharlitskaia, E.V., Beketova, T.P. 1989. Experimental antioxidant therapy in toxic liver damage from CCl4 and chloxyl. Patol Fiziol Eksp Ter. 4, 52-56.

[39] Szkudelski, T. 2001. The mechanism of alloxan and streptozotocin action in B cells of the rat pancreas. Physiol. Res. $50,537-546$.

[40] Victor, V.M., De la Fuente, M. 2003. Immune cells redox state from mice with endotoxin-induced oxidative stress. Involvement of NF-kB. Free Radic. Res. 37, 19-27.

[41] Borrelli, E., Roux-Lombard, P., Grau, G.E., Girardin, E., Ricou, B., Dayer, J., Suter, P.M. 1996. Plasma concentrations of cytokines, their soluble receptors, and antioxidant vitamins can predict the development of multiple organ failure in patients at risk. Crit. Care Med. 24, 392-7.

[42] Macdonald, J., Galley, H.F., Webster, N.R. 2003. Oxidative stress and gene expression in sepsis. Br. J. Anaesth. 90, 221-232.

[43] Durant, R., Klouche, K., Delbosc, S., et al. 2004. Superoxide anion overproduction in sepsis: effects of vitamin e and simvastatin. Shock. 22, 34-9. 
[44] Javesghani, D., Magder, S.A., Barreiro, E., Quinn, M.T., Hussain, S.N. 2002. Molecular characterization of a superoxide-generating NAD(P)H oxidase in the ventilatory muscles. Am. J. Respir. Crit. Care Med. 165, 412-418.

[45] Luchtemberg, M.N., Petronilho, F., Constantino, L., et al. 2008. Xanthine oxidase activity in patients with sepsis. Clin. Biochem. 41, 1186-1190.

[46] Garcia, J.J., Reiter, R.J., Guerrero, J.M., Escames, G., Yu, B.P., Oh, C.S., Munoz-Hoyos, A. 1997. Melatonin prevents changes in microsomal membrane fluidity during induced lipid peroxidation. FEBS Lett. 408, $297-300$.

[47] Tuon, L., Comim, C.M., Petronilho, F., Barichello, T., Izquierdo, I., Quevedo, J., Dal-Pizzol, F. 2008. Time-dependent behavioral recovery after sepsis in rats. Intensive care Med. 34, 1724-1731.

[48] Sener, G., Toklu, H., Ercan, F., Erkanli, G. 2005. Protective effect of $\beta$-glucan against oxidative organ injury in a rat model of sepsis. Int. Immunopharmacol. 5, 1387-1396.

[49] De Souza, L.F., Ritter, C., Pens Gelain, D., et al. 2007. Mitochondrial superoxide production is related to the control of cytokine release from peritoneal macrophage after antioxidant treatment in septic rats. J. Surg. Res. 141, 252-256.

[50] Supinski, G., Stofan, D., Callahan, L.A., Nethery, D., Nosek, T.M., DiMarco, A. 1999. Peroxynitrite induces contractile dysfunction and lipid peroxidation in the diaphragm. J. Appl. Physiol. 87, 783-791.

[51] Sener, G., Toklu, H., Kapucu, C., Ercan, F., Erkanlı, G., Kaçmaz, A., Tilki, M., Yegen, B.C. 2005. Melatonin protects against oxidative organ injury in a rat model of sepsis. Surg. Today. 35, 52-59.

[52] Ortolani, O., Conti, A., De Gaudio, A.R., Moraldi, E., Cantini, Q., Novelli, G. 2000. The effect of glutathione and NAcetylcysteine on lipoperoxidative damage in patients with early septic shock. Am. J. Respir. Crit. Care Med. 161, 1907-1911.

[53] Kharb, S., Singh, V., Ghalaut, P.S., Sharma, A., Singh, G.P. 2000. Role of oxygen free radicals in shock. J. Assoc. Physicians India. 48, 956-957.

[54] Schaich, K.M. 1992. Metals and lipid oxidation. Contemporary issues. Lipids. 27, 209-218.

[55] Okado-Matsumoto, A., Fridovich, I. 2001. Subcellular distribution of superoxide dismutases (SOD) in rat liver: Cu, ZnSOD in mitochondria. J. Biol. Chem. 276, 38388-93.

[56] Halliwell, B., Zhao, K., Whiteman, M. 1999. Nitric oxide and peroxynitrite: the ugly, the uglier and the not so good: a personal view of recent controversies. Free Radic. Res. 31, 651-669.

[57] Ratheesh, M., Shyni, G.L., Sindhu, G., Helen, A. 2011. Inhibitory effect of Ruta graveolens L. on oxidative damage, inflammation and aortic pathology in hypercholesteromic rats. Exp. Toxicol. Pathol. 63, 285-290.

[58] Husain, K., Somani, S.M. 1997. Interaction of exercise and ethanol on hepatic and plasma antioxidant system in rat. Pathophysiology. 4, 69-74.

[59] Kolgazi, M., Sener, G., Cetinel, S., Gedik, N., Alican, I. 2006. Resveratrol reduces renal and lung injury caused by sepsis in rats. J. Surg. Res. 134, 315-321.

[60] Hu, J.Y., Li, C.L., Wang, Y.W. 2012. Altered proteomic pattern in platelets of rats with sepsis. Blood Cells Mol. Dis. 48, 30-35.

[61] Yun, N., Lee, C.H., Lee, S.M. 2009. Protective effect of Aloe vera on polymicrobial sepsis in mice. Food Chem. Toxicol. 47, 1341-1348.

[62] Sato, M, Maulik, N., Das, D.K. 2002. Cardioprotection with alcohol: role of both alcohol and polyphenolic antioxidants. Ann NY Acad Sci. 957, 122-135.

[63] Deitch, E.A. 1992. Multiple organ failure. Pathophysiology and potential future therapy. Ann. Surg. 216, $117-134$.

[64] Pirouzpanah, S., Rashidi, M.R., Delazar, A., Razavieh, S.V., Hamidi, A. 2006. Inhibitory effects of Ruta graveolens L. extract on guinea pig liver aldehyde oxidase. Chem. Pharm. Bull. 54, 9-13.

[65] Khlifi, D., Sghaier, R.M., Amouri, S., Laouini, D., Hamdi, M., Bouajila, J. 2013. Composition and anti-oxidant, anticancer and anti-inflammatory activities of Artemisia herba-alba, Ruta chalepensis L. and Peganum harmala L. Food Chem. Toxicol. 55: 202-208.

[66] Razali, N., Razab, R., Junit, S.N., Aziz, A.A. 2008. Radical scavenging and reducing properties of extracts of cashew shoots (Anacardium occidentale). Food Chem. 111, 38-44.

[67] Almeida, I.F., Fernandes, E., Lima, J.L., Costa, P.C., Bahia, M.F. 2008. Protective effect of Castanea sativa and Quercus robur leaf extracts against oxygen and nitrogen reactive species. J. Photochem. Photobiol. B. 91, 87-95.

[68] Alejandro, D.B., Andreo, G., Susana, P. 2000. Effect of nitric oxide and plant antioxidants on microsomal content of lipid radicals. Biol. Res.. 33, 159-65.

[69] Hsu, C.Y. 2006. Antioxidant activity of extract from Polygonum aviculare L. Biol. Res. 39, $281-8$.

[70] Shahidi, F., Janitha, P.K., Wanasundara, P.D. 1992. Phenolic antioxidants. Crit. Rev. Food Sci. Nutr. 32, 67-103. 
[71] Ashour, M.N., Habib, D.F., Hanna, R.A., El-Dabaa, M.A.T. 2011. Beneficial effects of Curcumin and Ruta Chalepensis on the antioxidant system and inflammation in hypercholesteromic rats. Aust. J. Basic. Appl. Sci. 5, 2562-2567.

[72] Preethi, K.C., Kuttan, G., Kuttan, R. 2006. Anti-tumour activity of Ruta graveolens extract. Asian Pac. J. Cancer Prev. 7, 439-443.

[73] Fleming, T., et al. 2000. PDR for Herbal Medicines; Ed: medical economics company. p: 648-649

[74] Shen, S.C., Lee, W.R., Lin, H.Y., Huang, H.C., Ko, C.H., Yang, L.L., Chen, Y.C. 2002. In vitro and in vivo inhibitory activities of rutin, wogonin and quercetin on lipopolysaccharide-induced nitric oxide and prostaglandin E2 production. Eur. J. Pharmacol. 446, 187-194. 